\title{
The Role of Respiratory Infection in Sudden Infant Death Syndrome (SIDS)
}

\author{
David T. Mage1, Maria L. Latorre², Alejandro G. Jenik³, E. Maria Donner ${ }^{4}$
}

'WHO, Division of Environmental Health, Geneva, CH (now Newark, DE, USA) 18 W Periwinkle Lane. Newark DE, magedonner@aol.com ${ }^{2}$ Corporación Infancia Colombia Calle 127C \# 7 A -32 - Bogotá DC, Colombia, ml.latorre2010@gmail.com

${ }^{3}$ Servicio de Neonatología del Hospital Italiano de San Justo Agustín Rocca. Av.Presidente Perón 2231. San Justo. Provincia de Buenos Aires Argentina. 4959.0200, alejandro.jenik @hospitalitaliano.org.ar

${ }^{4}$ Dupont Haskell Global Centers for Health \& Environmental Sciences, Newark, DE, USA, 18 W. Periwinkle Lane. Newark DE. 19711-6212. USA, emdonner@aol.com

\begin{abstract}
:
Introduction: The Sudden Infant Death Syndrome (SIDS) is not likely to be explained by a currently measureable presence in all cases and absence in controls, as otherwise it would have been solved already. Indeed, any proposed physiological model for SIDS causation must explain the constant mathematical and statistical properties of SIDS age and gender. We have shown previously that SIDS are characterized by a common 4-parameter lognormal age distribution sparing neonatal infants, by a nominal $50 \%$ male excess, and by a higher rate in winter than summer. We test now whether SIDS is closely related to a fulminating prodromal Acute Respiratory Infection (ARI) by a common increasing rate with the infants increasing Live Birth Order (LBO), all remaining the same, independent of the change in preferred sleeping positions of the infants, prone or supine.

Methods: We use U.S. published infant mortality data from wonder.cdc.gov and other countries (Colombia, U.K., Europe, Australasia) to make comparisons between the two causes of death (ARI and SIDS) to evaluate how closely ARI resembles the characteristics of SIDS. Results: Gender: SIDS male excess 50\%, ARI male excess 50\%; Ages: SIDS 90\% post-neonatal,

ARI 96\% post-neonatal; Seasonality: SIDS and ARI are higher in winter than summer;

Live birth order: SIDS and ARI rates increase with increasing LBO with similar mathematical relationship.

Conclusion: Our results show that all SIDS are very likely relatable to a single cause tied to a fulminating prodromal ARI in a physiologically anemic infant who is genetically (X-link recessive) susceptible to cerebral anoxia. An alternative cause of all SIDS death by a collection of subsets of different causes, such as brainstem-related respiratory abnormalities and cardiac QT abnormalities, is not supported because they cannot all have the same age-gender-seasonal-familial-distributions of SIDS, required by Cramér's Theorem.
\end{abstract}

Keywords:

physiological anemia;X-link recessive;respiratory infection;4-parameter lognormal age distribution;cohabiting family members

\section{BACKGROUND}

The Sudden Infant Death Syndrome (SIDS) is one of the oldest unsolved mysteries of pediatric medicine. We have shown previously that: 1) SIDS cannot be a cardiac death, because SIDS has a constant $50 \%$ male excess and cardiac infant deaths have a $0 \%$ male excess [1-3]; 2) SIDS is not likely to be caused by a brainstem-abnormality because SIDS ages have a lognormal age distribution, sparing infants at or shortly after birth, whereas infants born with fatal neurological defects have maximum mortality shortly after birth [4-6]. Rather, we show that SIDS have the same gender distribution (50\% excess male rate) as infant deaths from respiratory infection $[5,7]$ and a similar 4-parameter lognormal age distribution as with hospital admissions for bronchiolitis [7]. We now address the known increasing risk of SIDS for an infant with their increasing order of live birth within their family that we propose is circumstantial evidence that a fulminating prodromal respiratory infection may be the cause of their death [8].

\section{The Infection Vector for SIDS}

The infant with an acute respiratory infection (ARI) must get it from contact with a carrier of that communicable infection which is most likely from one of their cohabiting family members (CFM) consisting of parents and older siblings [9]. We assume that the SIDS infant of a given live birth order (LBO) lives with both parents and all older siblings so that $\mathrm{CFM}=2$ parents + (LBO
- 1) siblings = LBO + 1. Table 1 shows the U.S. 1995-2013 infant mortality from Sudden Unexpected Infant Death (SUID), which are SIDS redefined by CDC as the total of SIDS + UNK (Unknown cause or SIDS with incomplete forensic investigation) + ASSB (Accidental Suffocation or Strangulation in Bed, or SIDS with possible suffocation from prone sleep position or face covering), and numbers at risk with a given LBO [5]. As readily seen in the next-to-last column, the rate of total SIDS (SUID) increases monotonically with LBO.

Table 1. U.S. 1995-2013, wonder.cdc.gov, SUID = SIDS + UNK + ASSB, male fraction 0.588 [5].

\begin{tabular}{ccccc}
\hline $\begin{array}{c}\text { Live Birth Order } \\
\text { (CFM) }\end{array}$ & $\begin{array}{c}\text { SIDS + UNK }+ \\
\text { ASSB }\end{array}$ & Infants at risk & $\begin{array}{c}\text { SUID rate per } \\
1000\end{array}$ & $\begin{array}{c}\text { SIDS Model per } \\
1000\end{array}$ \\
\hline $0(0)$ & 0 & 0 & 0 & 0 \\
$1(2)$ & 21,270 & $30,740,193$ & 0.6919 & 0.6754 \\
$2(3)$ & 22,886 & $24,528,771$ & 0.9330 & 0.9634 \\
$3(4)$ & 14,612 & $12,707,378$ & 1.1498 & 1.2225 \\
$4(5)$ & 7,329 & $5,081,597$ & 1.4422 & 1.4558 \\
$5(6)$ & 3,178 & $1,890,067$ & 1.6814 & 1.6657 \\
$6(7)$ & 2,802 & $1,470,973$ & 1.9046 & 1.8546 \\
\hline
\end{tabular}

We noted the increase of the SIDS rate as CFM increases and developed the following probability model to express the concave shape of the relationship. Let $\mathrm{P}$ equal the average probability that a CFM does not bring 
home a communicable respiratory infection. If the infant lives with CFM first order relatives then the probability that none of them is a carrier is $\mathrm{P}^{\wedge} \mathrm{CFM}$. Therefore, the probability that the infant is exposed to at least one carrier CFM is 1 - $P \wedge C F M$. Our model fit to these data is that $P=0.9$ and the SIDS rate per 1000 at risk with a given $\angle B O=3.55^{*}\left(1-0.9^{\wedge} \mathrm{CFM}\right)$. Figure 1 shows the goodness of fit of the model to these data. Note how the model goes to the origin (0 SIDS for cloned infants that have 0 CFM contacts), smoothly without any discontinuity. Therefore all SIDS are related to a possible source of an ARI.

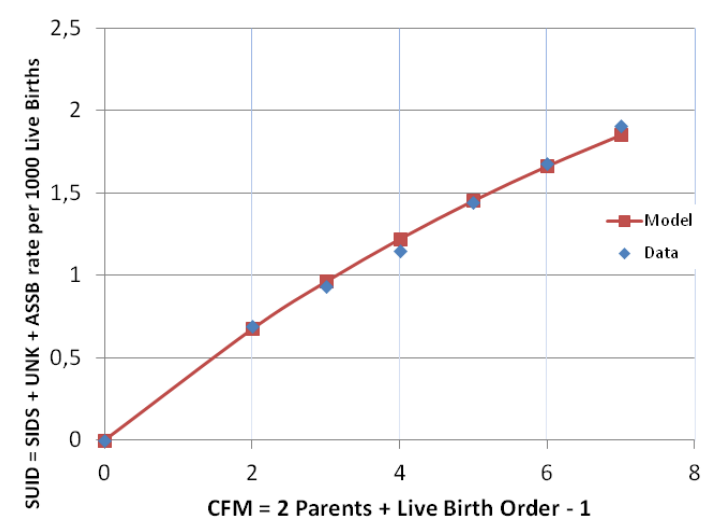

Figure 1. U.S. 1995 - 2013 SUID rate/1000 increasing with family size CFM as a respiratory infection vector, with rate $=3.55^{*}\left(1-0.9^{\wedge \text { CFM }}\right)$

Table 2 shows the total number of U.S. SIDS (9ICD 798.0) of Whites and American Indians from the paper by Pezzino and lyasu [10] as a function of their live birth order, with a total male fraction of 0.621 . As shown for all races in the U.S. 1995-2013, the SIDS rate increases with the same form that we model here as $4.5^{*}\left(1-0.9^{\wedge \mathrm{CFM}}\right)$ per 1000 at risk. Figure 2 shows this same relational form as Figure 1.

Table 2. U.S. 1983-1987. SIDS of White and American Indian infants, male fraction $=0.621$

\begin{tabular}{ccccc}
\hline $\begin{array}{c}\text { Live Birth Order } \\
\text { (CFM) }\end{array}$ & $\begin{array}{c}\text { SIDS 9ICD } \\
798.0\end{array}$ & Infants at risk & $\begin{array}{c}\text { Rate per } \\
1000\end{array}$ & $\begin{array}{c}\text { Model Rate per } 10004.5^{*} \\
\left(1-0.9 \wedge \wedge^{C F M}\right)[9]\end{array}$ \\
\hline $0(0)$ & 0 & 0 & 0 & 0 \\
$1(2)$ & 5,951 & $6,158,352$ & 0.9663 & 0.8550 \\
$2(3)$ & 6,481 & $4,726,397$ & 1.3712 & 1.2195 \\
$3(4)$ & 3,283 & $2,157,395$ & 1.5217 & 1.5475 \\
$4(5)$ & $\mathbf{2 , 0 1 7}$ & $\mathbf{1 , 1 6 5 , 4 3 5}$ & $\mathbf{1 . 7 3 0 6}$ & $\mathbf{1 . 8 4 2 7}$ \\
\hline
\end{tabular}

Table 3 shows SIDS LBO for Colombia, a semi-tropical South American country with a quite different climate and multiracial population than for North America and Europe [11,12]. Their child-care traditions and medical systems also have differences that may lead to difficulty in making international comparison. For instance, whereas the U.S. has decomposed earlier SIDS cases ICD-9 798.0 into ICD-10 SUID = SIDS (R95) + Unknown via absence of forensic autopsy (R99) + Accidental suffocation or strangulation in bed (ASSB) W75, Colombia lists the latter cases with category of ASSB under the rubric ICD-10 R98 as Unattended Death. Table 3 lists these cases and at risk birth populations as SUID = R95 + R98 + R99 for 2008-2013.

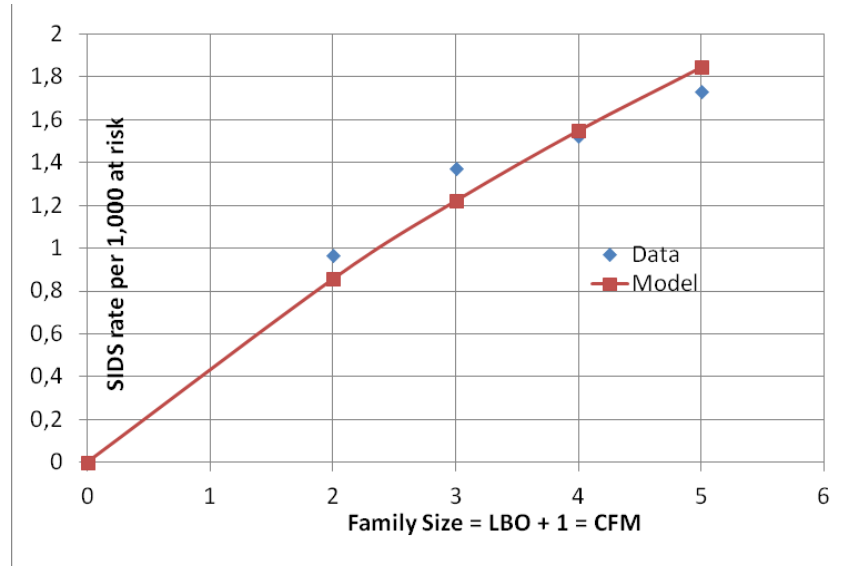

Figure 2. U.S. 1983 - 1987 White and American Indian SIDS rate/1000 increasing with family size as a respiratory infection vector, with model rate $=4.5^{*}\left(1-0.9^{\wedge}\right.$ CFM $)$

Table 3. Colombia 2008-2013, SUID = R95, R98, R99 [11,12]

\begin{tabular}{ccccc}
\hline $\begin{array}{c}\text { Live Birth } \\
\text { Order } \\
\text { (CFM) }\end{array}$ & SIDS R95, R98, R99 & Infants at risk & Rate per 1000 & $\begin{array}{c}\text { Model Rate per } 1000 \\
=0.6^{*}(1-0.9 \wedge \text { (FM) }\end{array}$ \\
\hline $0(0)$ & 0 & 0 & 0 & 0 \\
$1(2)$ & 317 & $1,858,872$ & 0.1705 & 0.1140 \\
$2(3)$ & 179 & $1,208,067$ & 0.1481 & 0.1626 \\
$3(4)$ & 113 & 552,283 & 0.2046 & 0.2063 \\
$4(5)$ & 44 & 220,025 & 0.1999 & 0.2457 \\
$5(6)$ & 27 & 99,290 & 0.2719 & 0.2811 \\
$6(7)$ & 16 & 49,327 & 0.3243 & 0.3130 \\
$7(8)$ & 9 & 25,393 & 0.3544 & 0.3417 \\
\hline
\end{tabular}

Source: DANE [12]

Figure 3 shows these Colombian SUID data can also be modeled using the same form of the equation used for the U.S. SIDS/SUDI data in Figures 1 and 2 . In this case the model is SUID rate $=0.6 *\left(1-0.9{ }^{\wedge}{ }^{\text {CFM }}\right)$ per 1000 live births at each LBO.

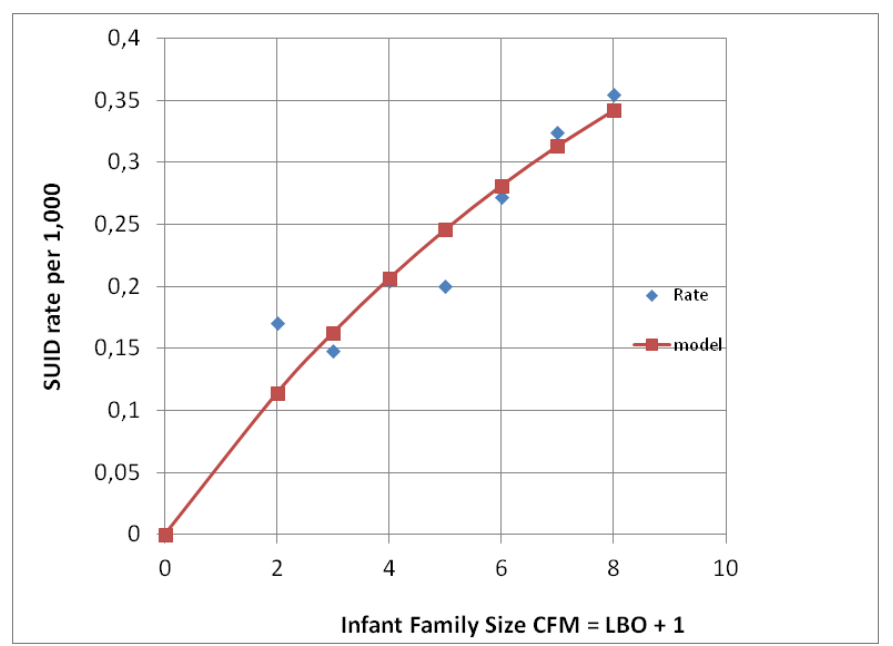

Figure 3. Colombia 2008-2013 SUID (R95, R98, R99) rate/1000 increasing with family size as a respiratory infection vector, with model rate $=0.6^{*}(1$ $-0.9^{\wedge \text { CFM) }}$ 


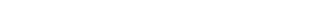

Table 4 lists the international data on live birth order of 1,449 SIDS compiled by Carpenter et al. from studies by the European Concentrated Action on SIDS (ECAS) of some 20 countries, and additional non-ECAS SIDS cases from Ireland, Scotland, and New Zealand [13]. They also collected data on 4,654 controls from all these studies, both matched and unmatched. Note that this study reported rates differently than the other studies discussed in this paper. Here the SIDS were random samples from multiple studies and the controls were random samples from matched and non-matched nonSIDS control infants from the same countries and years. It is interesting to note that of the 1466 SIDS cases reported (17 without live birth order) there were 898 male SIDS giving a total male fraction of $898 / 1466=0.613$ male that is virtually identical to the 0.612 male fraction we reported that was the basis for our recessive $X$-linkage model for SIDS and other respiratory causes of death $[1,14]$.

Table 4. U.K., Europe and New Zealand. Carpenter et al. 2013. SIDS R95 [13]

\begin{tabular}{cccccc}
\hline $\begin{array}{c}\text { Live Birth } \\
\text { Order } \\
\text { (CFM) }\end{array}$ & $\begin{array}{c}\text { SIDS } \\
\text { R95 }\end{array}$ & $\begin{array}{c}\text { Con- } \\
\text { trols }\end{array}$ & $\begin{array}{c}\text { SIDS+ } \\
\text { Controls }\end{array}$ & $\begin{array}{c}\text { SIDS Rate per } \\
1,000 \text { SIDS + Controls }\end{array}$ & $\begin{array}{c}\text { Model Rate per } \\
1,0000.792^{*}(1- \\
0.9 \wedge^{(\mathrm{CFM})}\end{array}$ \\
\hline $0(0)$ & 0 & 0 & 0 & 0 & 0 \\
$1(2)$ & 407 & 1,836 & 2,243 & 0.18145 & 0.15675 \\
$2(3)$ & 491 & 1,566 & 2,057 & 0.23869 & 0.22357 \\
$3(4)$ & 280 & 748 & 1,028 & 0.27237 & 0.28371 \\
$4(5)$ & 149 & 304 & 453 & 0.32891 & 0.33784 \\
$5(6)$ & 122 & 200 & 322 & 0.37888 & 0.38656 \\
\hline
\end{tabular}

Figure 4 shows these ECAS data can also be modeled using the same form of the equation used for the U.S. SIDS/SUDI data in Figures 1 and 2. In this case the model is SIDS rate $=0.792^{*}\left(1-0.9^{\wedge}{ }^{\mathrm{CFM}}\right)$ per 1000 live births at each LBO.

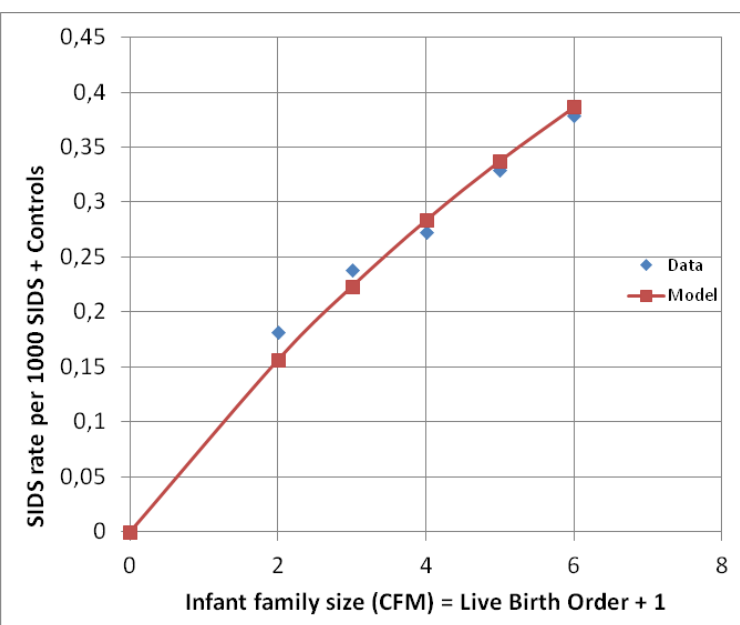

Figure 4. International SIDS rate/1000 increasing with $C F M=L B O+1$ as a respiratory infection vector, rate $=0.792^{*}\left(1-0.9^{\wedge C F M}\right)$

Table 5 shows the U.S. infant mortality rate from both Upper and Lower Acute Respiratory Infections (ARI) from 1995-2013 [5]. The corresponding codes are ICD-10, J00-J06, J20-J22, ICD-9 460-466. As for SIDS, the ARI mortality rate increases with (CFM) in Figure 5, and with a similar mathematical relationship for prediction as from Colombia in Figure 3. Colombia, unlike the U.S., has no cold winter season, and maximal infant respiratory infection and SIDS both occur during the rainy season. Thus, this supports our finding that SIDS appears to have a causal relationship to the initial fulmination of a prodromal ARI that may cause neuronal death in the physiologically susceptible infants [8]. We note that many U.S. medical examiners do not culture lung exudate of potential SIDS cases because "of a perceived lack of testing utility" [15], and that in many cases the cultures are negative in spite of other evidence of severe sepsis [16].

Table 5. U.S. 1995-2013. wonder.cdc.gov. Acute upper and lower respiratory infection mortality. ICD-10 J00-J06, J20-J22, ICD-9 460-466. [5]

\begin{tabular}{ccccc}
\hline $\begin{array}{c}\text { Live Birth } \\
\text { Order } \\
\text { (CFM) }\end{array}$ & $\begin{array}{c}\text { ARI J00-J06, } \\
\text { J20-J22 } \\
\text { 9ICD 460-466 }\end{array}$ & $\begin{array}{c}\text { Infants at } \\
\text { risk }\end{array}$ & $\begin{array}{c}\text { Rate per } \\
100,000\end{array}$ & $\begin{array}{c}\text { Model Rate per } \\
100,000=0.636^{*} \\
\left(1-0.9 \wedge \wedge^{(F M)}\right.\end{array}$ \\
\hline $0(0)$ & 0 & 0 & 0 & 0 \\
$1(2)$ & 280 & $30,740,193$ & 0.9108 & 1.2084 \\
$2(3)$ & 387 & $24,528,771$ & 1.5777 & 1.7235 \\
$3(4)$ & 265 & $12,707,378$ & 2.0854 & 2.1872 \\
$4(5)$ & 139 & $5,081,597$ & 2.7353 & 2.6044 \\
$5(6)$ & 58 & $1,890,067$ & 3.0686 & 2.9800 \\
$6(7)$ & 50 & $1,470,973$ & 3.3991 & 3.3180 \\
\hline
\end{tabular}

Figure 5 shows the same relationship for ARI to LBO as SIDS and SUID.

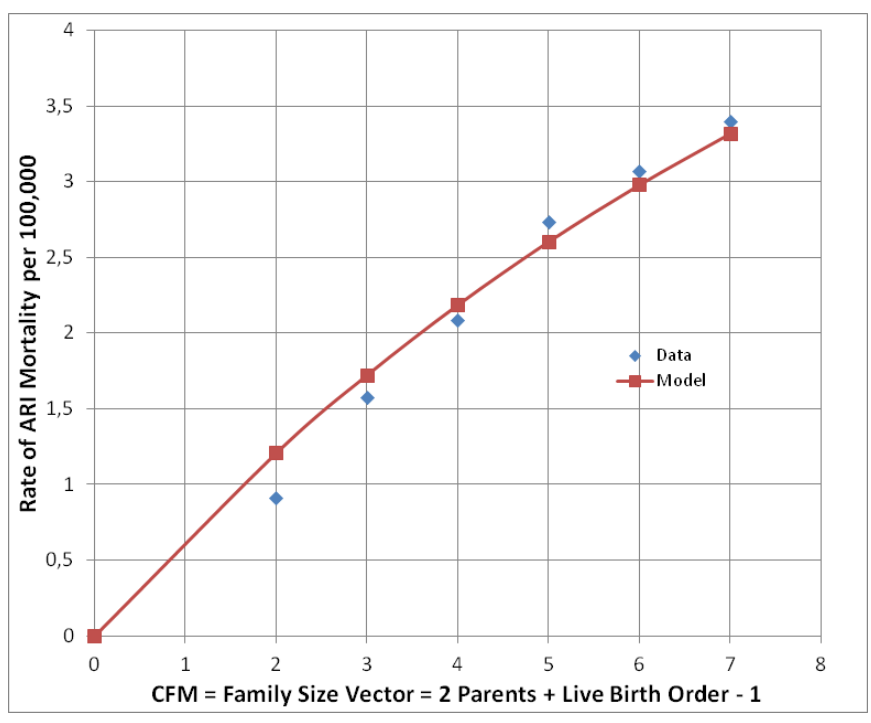

Figure 5. U.S. 1995 - 2013 ARI rate/100,000 increasing with CFM as a respiratory infection vector, with rate $=6.36^{*}\left(1-0.9^{\wedge C F M}\right)$

\section{Encephalopathy, Unspecified (EU):}

The U.S. National Institute of Neurological Disorders and Stroke (NINDS) describes encephalopathy as "any diffuse disease of the brain that alters brain function or structure." That is, in common usage, "any brain disease, disorder or disease of the brain, dysfunction of the brain, degeneration of brain function, and brain damage or malfunction."(17) The U.S. CDC lists encephalopathy, unspecified (EU ICD-10 G93.4), as a cause of infant death without specific indication of which areas of the brain may be involved (5). Consequently, possibly SIDS-related medullary seratonergic deficits that may develop during gestation when the medullary seratonergic system 
is forming, are not necessarily included in these EU causes of death. For example, a suboptimal intrauterine environment, with hypoxia from iron deficiency anemia, is known to cause neurological abnormality $(6,18)$. Therefore, we only propose that the relations we show herein for death by EU only apply to unspecified locus encephalopathy in general. Thus, they cannot be definitively shown to apply to the serotonergic medulla abnormalities that have been proposed to apply to a partial subset of SIDS (19). We also note recent discussion of the difficulty of discerning between cerebral post-mortem changes and ante-mortem ischemic injury (20).

In comparison to SIDS and ARI which have increasing risks of mortality with increasing family size as potential carriers of an ARI, infant mortality from $E U$ is relatively independent of the infant's family size or live birth order. Table 6 shows U.S. data on this cause [5].

Table 6. U.S. 1995-2013. EU death, CDC wonder.cdc.gov ICD-10 G93.4, ICD-9 $348.3[5]$

\begin{tabular}{ccccc}
\hline $\begin{array}{c}\text { Live Birth Order } \\
\text { (CFM) }\end{array}$ & $\begin{array}{c}\text { Encephalopathy } \\
\text { Unspecified } \\
\text { ICD-10 G93.4 } \\
\text { ICD-9348.3 }\end{array}$ & Infants at risk & $\begin{array}{c}\text { Rate per } \\
10,000\end{array}$ & $\begin{array}{c}\text { No appropriate } \\
\text { model for BAE }\end{array}$ \\
\hline $1(2)$ & 200 & $30,740,193$ & 0.06505 & - \\
$2(3)$ & 152 & $24,528,771$ & 0.06197 & - \\
$3(4)$ & 67 & $12,707,378$ & 0.05272 & - \\
$4(5)$ & 29 & $5,081,597$ & 0.05706 & - \\
$5(6)$ & 12 & $1,890,067$ & 0.06349 & - \\
$6(7)$ & 13 & $1,470,093$ & 0.08838 & - \\
\hline
\end{tabular}

Figure 6 shows that the family size of the infant dying from EU, has no consistent relation to family size or LBO. In addition, $60 \%$ of these infants die from EU in the first 4 weeks of life, but SIDS spares the neonate [4-6].

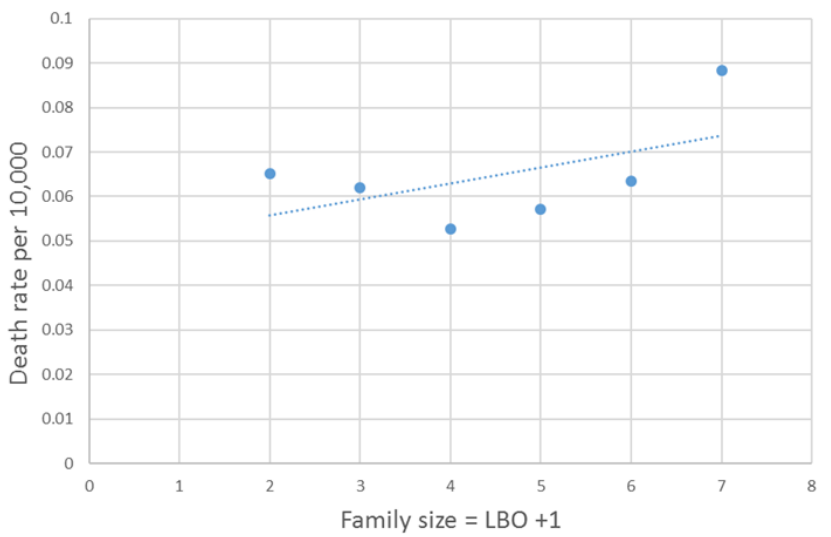

Figure 6. U.S. 1995-2013 Encephalopathy, Unspecified rate per 10,000 not steadily increasing with family size $(\mathrm{LBO}+1)$

Figures 7 and 8 show that the age distribution of SIDS and Hospital admissions for bronchiolitis in Scotland 1982-1990, have the same lognormal form, as well as the same male fractions (SIDS 0.612 and Bronchiolitis 0.614). Gupta et al. [7] came to the conclusion that "the two conditions do not appear to be closely related" by a chi-square test and analyses of their autocorrelation structures. They attributed the bronchiolitis hospitalization cases to the ubiquitous respiratory syncytial virus (RSV) to which virtually all infants are exposed by the end of the second year of life. However, there are several reasons why the statistical comparison between SIDS and RSV hospitalization may show no significant relation if one did exist:

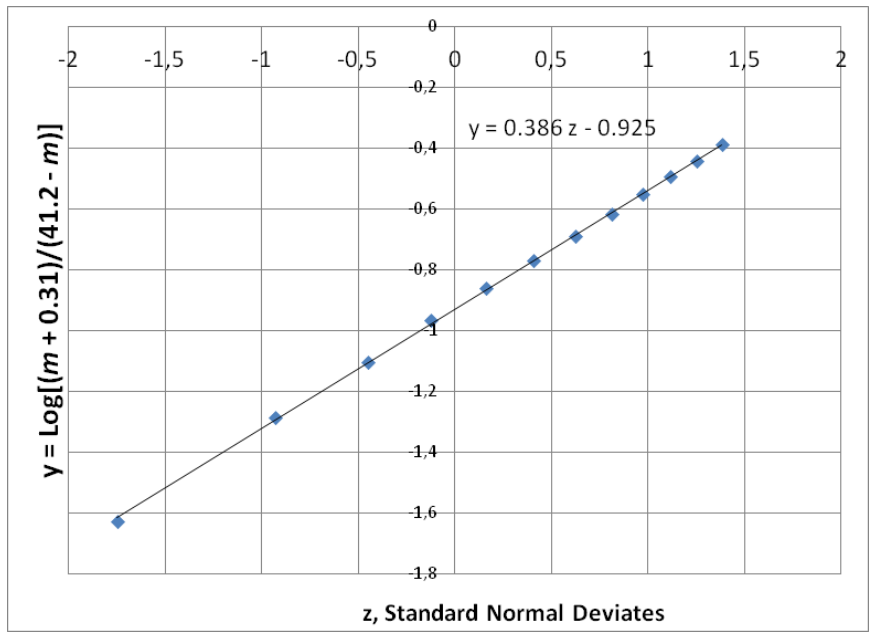

Figure 7. Monthly $(\mathrm{m})$ age distribution of Bronchiolitis Hospital admissions in Scotland, 1982-1990 Gupta et al. [7]

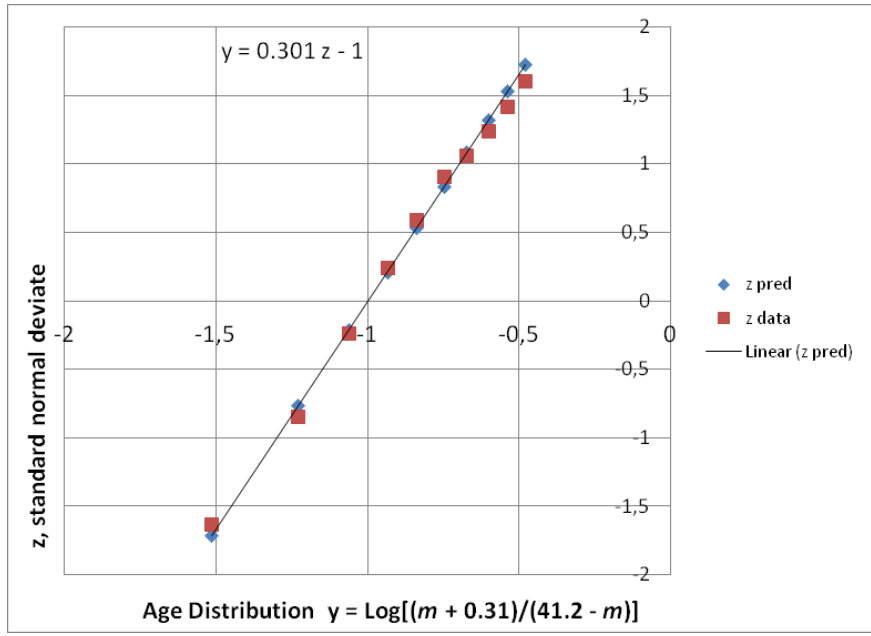

Figure 8. Monthly $(\mathrm{m})$ age distribution of SIDS Scotland, 1982-1990, Gupta et al. [7]

All statistical testing assumes that measurements are made without error, but SIDS have false positives and false negatives. Thus Recorded SIDS $($ RS) $=$ Actual SIDS (AS) + False Positives (FP) - False Negatives (FN). Therefore the expected variance of RS = Sum of variances of AS + FP + FN. But not all $N$ infant RSV infections lead either to actual SIDS (AS) or admission for hospitalization (HA) for bronchiolitis. If healthy infants first receive an RSV and do not die of SIDS, we assume they either receive home medical treatment (HMT) or are admitted to hospital for treatment (HA). Therefore $\mathrm{HA}=\mathrm{N}-\mathrm{AS}-\mathrm{HMT}$. Then from statistical theory the expected variance of $\mathrm{HA}=$ Sum of variances of N, RS, FP, FN and HMT. In addition, not all ARI are caused by RSV [8]. Therefore, SIDS should have been compared to all infant hospitalizations for upper and lower ARI, not just those for bronchiolitis.

In summary, we have shown here, and in other SJFS papers [21-23], the following mathematical relationships that SIDS display, and must be explained by any other proposed cause for SIDS, while obeying Cramér's 
Theorem [24] because SIDS ages have a normal transform distribution:

1) The constant $50 \%$ male excess rate compared to the female rate for equal numbers of infants at risk. Given the nominal $5 \%$ excess male birth rate this leads to the observed male fraction of $0.61[1,25]$;

2) The left-censored 4-parameter lognormal (Johnson $S_{B}$ ) age distribution that has $3 \mathrm{rd}$ and 4 th parameters of order -0.31 and 41.2 months with median of approximately -1 and approximate standard deviation of 0.3 ;

3) The increased risk of SIDS with the infant's increasing numbers of older siblings by the factor $\left(1-0.9^{\wedge \mathrm{CFM}}\right)$ where CFM $=2$ parents $+(\mathrm{LBO}-1)$ siblings, and;

4) Maximum SIDS rate in winter months and minimum rate in summer months [26].

To our knowledge, no other cause of SIDS has been proposed that meets these essential conditions that are necessary, but insufficient, to prove that they are the cause of SIDS. For proof of its causation, the predicted missing $X$-linked $p=1 / 3$ dominant allele that is protective of neuronal cell death by acute anoxic encephalopathy by enabling the infant to shift from aerobic to anaerobic oxidation must be identified [3, 14]. This may be difficult because of the likely presence of false positive SIDS in the study cohorts, where a non-SIDS cardiac cause of death or a case of infanticide may have been missed. In addition, our model requires that the SIDS infant be in the lowest percentile $(-2 \sigma)$ of hemoglobin from the natural physiological anemia that occurs for all infants between 2 and 3 months of age [27-30]. However, due to the gravitational settling of the red blood cells (RBC) during hemostasis leading to lividity, an accurate blood $\mathrm{Hb}$ cannot be measured. If all infants in a birth cohort had their blood $\mathrm{Hb}$ measured at birth then perhaps the lowest $\mathrm{Hb}$ infants could be identified as the susceptible cohort and treated to increase their $\mathrm{Hb}$.

In conclusion, we propose that if the most physiologic-anemic infants can be identified and treated, and if the enzyme coded for by a protective putative dominant X-linked allele can be identified and given to the unprotected infant, then it may be possible to reduce infant mortality significantly by reducing the numbers of infants dying from all respiratory causes [31].

\section{REFERENCES}

[1] Mage DT, Donner M. A genetic basis for the sudden infant death syndrome sex ratio. Med Hypotheses. 1997 Feb;48(2):137-142.

[2] Mage DT, Donner EM. The fifty percent male excess of infant respiratory mortality Acta Paediatr. 2004 Sep;93(9):1210-1215.

[3] Mage DT, Donner EM. Is excess male infant mortality from sudden infant death syndrome and other respiratory diseases X-linked? Acta Paediatr. 2014 Feb;103(2):188-193.

[4] Mage DT. A probability model for the age distribution of SIDS. JSIDS \& Infant Mortality 1996;1 (1):13-31.

[5] United States Department of Health and Human Services (US DHHS), Centers of Disease Control and Prevention (CDC), National Center for Health Statistics (NCHS), Division of Vital Statistics (DVS). Linked Birth / Infant Death Records 19952013. Last accessed at http://wonder.cdc.gov/lbd-current.html on Mar 4, 2016 2:54:13 PM

[6] Guntheroth WG, Spiers PS (2007) The triple risk hypotheses in Sudden Infant Death Syndrome. Pediatrics 110: e64.

[7] Gupta R, Helms PJ, Jolliffe IT, Douglas AS. Seasonal variation in sudden infant death syndrome and bronchiolitis--a common mechanism? Am J Respir Crit Care Med. 1996 Aug;154(2 Pt 1):431-435.

[8] Farber S. Fulminating streptococcus infections in infancy as a cause of sudden death. NEJM. 1934;211:154-158.

[9] Musher DM. How contagious are common respiratory tract infections? N Engl J Med 2003;348:1256-1266. http://www.health.harvard.edu/family_health_guide/ respiratory-tract-infection-is-it-contagious-the-family-healthguide. Accessed April 26, 2015

[10] Pezzino G, lyasu S. Sudden Infant Death Syndrome among American Indians. 1996. J SIDS and Infant Mortality 1;1:3-11.)

[11] Latorre ML, Barbosa S, Hernández LJ, Mage DT. (2015). Síndrome Infantil de Muerte Súbita (SIMS) y otras Súbitas e Inesperadas Muertes Infantiles (SIMI): uso de un modelo logarítmico para analizar el comportamiento epidemiológico en Bogotá y en Colombia, entre los años 2005 y 2010. Revista Colombiana de Pediatría. 48;1:9-14.

[12] Statistics Colombia. 2014 - DANE/Censos y Demografía - EEVV por Número de Hijos Nacidos Vivos de la Madre

[13] Carpenter R, McGarvey C, Mitchell EA, Tappin DM, Vennemann MM, Smuk M, Carpenter JR. Bed sharing when parents do not smoke: is there a risk of SIDS? An individual level analysis of five major case-control studies. BMJ Open. 2013 May 28;3(5). pii: e002299. doi: 10.1136/bmjopen-2012-002299.

[14] Naeye RL, Burt LS, Wright DL, Blanc WA, Tatter D. Neonatal mortality, the male disadvantage. Pediatrics. 1971 Dec;48(6):902-906.

[15] Brooks EG, Gill JR; National Association of Medical Examiners NAME Ad Hoc Committee for Bioterrorism and Infectious Disease. Testing for Infectious Diseases in Sudden Unexpected Infant Death: A Survey of Medical Examiner and Coroner Offices in the United States. Pediatr. 2015 Jul;167(1):178-82.e1. doi: 10.1016/j. jpeds.2015.04.007.

[16] Phua J, Ngerng W, See K, Tay C, Kiong T, Lim H, Chew M, Yip H, Tan A, Khalizah H, Capistrano R, Lee K, Mukhopadhyay A. Characteristics and outcomes of culturenegative versus culture-positive severe sepsis. Crit Care. 2013 Sep 12;17(5):R202. doi: $10.1186 /$ cc1289620

[17] Pinson R. Encephalopathy. ACP Hospitalist, January 2015

[18] Hardy JB, Drage JS, Jackson EC. The First Year of Life. The Collaborative Perinatal Project of the National Institute of Neurological and Communicative Disorders. 1979 The Johns Hopkins University Press, Baltimore.

[19] Kinney HC, Cryan JB, Haynes RL, Paterson DS, et al. Dentate gyrus abnormalities in sudden unexplained death in infants: morphological marker of underlying brain vulnerability. Acta Neuropathol. 2015 Jan;129(1):65-80. doi:10.1007/s00401-0141357-0. Epub 2014 Nov 25. PubMed PMID: 25421424

[20] Montaldo P, Chaban B, Lally PJ, Sebire NJ, et al. Quantification of antemortem hypoxic ischemic brain injury by post-mortem cerebral magnetic resonance imaging in neonatal encephalopathy. Eur J Paediatr Neurol. 2015 
Nov;19(6):665-71. doi:10.1016/j.ejpn.2015.07.006.

[21] Mage DT. Commentary of Blair et al. Scand J Forensic Sci, 2009;15:6-9. Scand J Forensic Sci, 2010;16(1):12-13

[22] Mage DT, Donner EM. The universal age distribution of the Sudden Infant Death Syndrome, Scand J Forensic Sci. 2011;17:7-10.

[23] Mage DT, Donner EM, Vennemann M, Fleming P, Sol-Church K, Drake R, Gulino SP. All sudden infant respiratory deaths may result from the same underlying mechanism. Scand J Forensic Sci. 2012;18(1):2-10.

[24] Mage DT, Donner M. Cramér's Theorem proves that SIDS is a distinct entity and not a collection of different causes of death. J Paediatrics and Child Health 2010;46 (Supplement 3, October):15.

[25] Thach B. Tragic and sudden death. Potential and proven mechanisms causing sudden infant death syndrome. EMBO Rep. 2008 Feb;9(2):114-8. doi: 10.1038/ sj.embor.7401163.
[26] Mage DT. Seasonal Variation of Sudden Infant Death Syndrome in Hawaii. Journal of Epidemiology \& Community Health. 2004;58 (11):912-916.

[27] O'Brien RT, Pearson HA. Physiologic anemia of the newborn infant. J Pediat 1971;79:132-138.

[28] Dallman PR. Anemia of Prematurity. Ann Rev Med 1981;32:143-160

[29] Poets CF, Samuels MP, Wardrop CA, et al. Reduced haemoglobin levels in infants presenting with apparent life-threatening events--a retrospective investigation. Acta Paediatr. 1992;81(4):319-321.

[30] Koenig HM, Lightsey AL. Growth curves for hemoglobin and red cell size during infancy. Unpublished. Personal communication, S. Lew, July 1982.

[31] Mage DT, Donner EM. An explanation of the $25 \%$ male excess mortality for all children under 5. Scand J Forensic Science 2015;21(1):91-100. 